\title{
Hipomagnesemia secundária ao uso crônico de Inibidores de Bomba de Prótons: Relato de Caso
}

\section{Hypomagnesaemia due to chronic use of Proton Pump Inhibitor: case report}

\author{
Renan F. F. Nunes ${ }^{1}$, Marcos A. Souza1, Wogelsanger O. Pereira², Lelyanne R. P. Torquato³, \\ Felipe L. Guedes ${ }^{4}$
}

\begin{abstract}
RESUMO
Modelo do Estudo: Relato de Caso. Objetivos: Apresentar um caso de hipomagnesemia sintomática associada a hipocalcemia induzido pelo uso de Omeprazol por cerca de 6 anos, com respectiva revisão de literatura. Métodos: Estudo dos achados clínicos e laboratoriais, associado à discussão da origem multifatorial do problema em questão. Relato de Caso: Paciente apresentou, há 2 meses, um episódio de convulsão e tremores, e outra convulsão à admissão, além de outros sinais clínicos de deficiência de magnésio, como parestesias, tremores e cãibras. Exames sanguíneos de acompanhamento de internação revelaram baixos valores séricos de cálcio $(8,0 \mathrm{mg} / \mathrm{dL})$ e magnésio $(0,94 \mathrm{mg} / \mathrm{dL})$, e níveis de sódio, potássio, uréia, creatinina e vitamina $\mathrm{D}$ dentro da normalidade. Dentre os medicamentos dos quais fazia uso, o Omeprazol era utilizado em regime de cronicidade, estando presente à admissão e nos 6 anos anteriores. A reposição de magnésio resultou em aumento parcial da concentração sérica $(1,30 \mathrm{mg} / \mathrm{dL}) \mathrm{e}$ melhora parcial da sintomatologia apresentada. Após a retirada do Omeprazol, os valores séricos de magnésio voltaram ao padrão de normalidade $(2,50 \mathrm{mg} / \mathrm{dL})$, ocorrendo remissão total dos sintomas. Importância: A Hipomagnesemia induzida pelo uso crônico de inibidores da bomba de prótons (IBP) é uma condição que pode levar a consequências clínicas graves, e tal situação pode ser revertida pela simples suspensão da medicação, medida capaz de restaurar o equilíbrio homeostático do magnésio.
\end{abstract}

Palavras-chave: Hipomagnesemia; Omeprazol; Hipocalcemia.

\begin{abstract}
Design of the study: Case report. Objectives: To present, through a case report, a framework of symptomatic hypomagnesaemia associated with hypocalcemia induced by the use of Omeprazole for a long period of time. Methods: Study of clinical and laboratory findings associated with the discussion of the multifactorial origin of the problem in question. Results: The patient depicted in this study showed clinical signs of magnesium depletion or deficiency, evidenced by seizures, tremors, cramps and paresthesias.
\end{abstract}

1. Acadêmicos do Curso de Medicina da Universidade do Estado do Rio Grande do Norte (UERN)

2. Professor Adjunto IV do Curso de Medicina da UERN. Doutor em Ciências da Saúde pela UNIFESP

3. Médica Residente em Nefrologia pelo Hospital Onofre Lopes (HUOL) da UFRN

4. Médico Nefrologista pela Universidade de São Paulo (USP) Ribeirão Preto
Correspondência: Renan Flávio de França Nunes. R. Pau-Brasil, no 457 - Nova Parnamirim. CEP: 59150-660, Natal, RN.

Artigo recebido em 30/01/2014 Aprovado para publicação em 28/08/2014 
Blood tests for monitoring of admission revealed low levels of calcium $(8,0 \mathrm{mg} / \mathrm{dL})$ and magnesium $(0,94$ $\mathrm{mg} / \mathrm{dL}$ ), with values of sodium, potassium, urea, creatinine and vitamin $\mathrm{D}$ within normal limits. The patient was using Omeprazole at admission. After the withdrawal of Omeprazole, serum magnesium returned to normal range and clinical ceased. Relevance: Hypomagnesaemia is a clinical condition of difficult to diagnose and rarely appears as a differential diagnosis. Chronic administration of proton pump inhibitors represents one of the possible genesis of this change of magnesium and should be considered as a potential cause of harm and should be promptly identified and treated with the suspension of the inhibitor.

Key words: Hypomagnesaemia; Omeprazole; Hypocalcemia.

\section{Introdução}

O Magnésio $(\mathrm{Mg})$ é essencial para o funcionamento de mais de 300 reações enzimáticas celulares que envolvem ATP, participando nelas como cofator, como é o caso das "bombas" Na-K-ATPase e HATPase. No organismo, como parte da homeostase, há um balanço interno desse íon, havendo constante troca entre os meios intra e extracelular. ${ }^{1,2}$ A hipomagnesemia pode causar diversas manifestações clínicas como fraqueza muscular, convulsões, depressão, arritmias, hipoparatireoidismo e hipocalemia, que, se não tratadas a tempo, podem levar o paciente a sérios problemas. ${ }^{1,3}$

A hipomagnesemia ocorre quando a concentração plasmática do íon $\mathrm{Mg}$ cai abaixo de $1,60 \mathrm{mg} / \mathrm{dL}$ $(0,80 \mathrm{mmol} / \mathrm{L} ; 1,40 \mathrm{mEq} / \mathrm{L})$. Essa alteração é diagnosticada em $12 \%$ a $53 \%$ dos pacientes internados em enfermarias gerais, variação atribuída ao tipo de população utilizada e à definição dos níveis inferiores de normalidade, mas que é mais comum em pacientes internados nos Serviços de Emergência e Unidades de Terapia Intensiva ${ }^{4}$; e é geralmente decorrente de perdas gastrointestinais (vômitos, diarreias, sonda nasogástrica em drenagem), renais (uso de medicamentos - como os diuréticos, na fase poliúrica da necrose tubular aguda, associado à hipocalemia), de redistribuição corporal (uso de insulina, infusão de glicose e de aminoácidos), e carencial (desnutrição, alcoolismo).

Recentemente, drogas como inibidores de bombas de prótons (IBP) tem sido implicadas na diminuição das concentrações séricas de Mg. ${ }^{1,3,5}$ Desde 2007, o British National Formulary inclui a hipomagnesemia como um dos possíveis efeitos do uso dos IBP. Em 2011, a Food and Drug Administration (FDA) apresentou um comunicado informando que a prescrição de IBP pode causar baixa nos níveis séricos de $\mathrm{Mg}$, principalmente com o uso prolongado. Entretanto, essa associação ainda é pouco conhecida. ${ }^{2,6,7}$
A correção da hipomagnesemia associada ao uso dos IBP necessita da interrupção do uso dessa droga, tendo em vista que a sua normalização não é obtida apenas pela reposição de Mg através de infusão venosa, como visto em estudos por Epstein et al. ${ }^{8}$ e Agarwal et al. ${ }^{9}$ Em ambos, a reposição não foi suficiente para alcançar níveis normais de $\mathrm{Mg}$. Por isso, especula-se que os IBP tenham um papel de inibir, de alguma maneira, a absorção gastrointestinal de Mg.

Relatamos aqui o caso de paciente idosa com alterações neurológicas e hipomagnesemia associada ao uso prolongado de IBP, cuja melhora foi obtida com reposição do magnésio e interrupção do uso da medicação.

\section{Relato de Caso}

Uma idosa de 81 anos, branca, foi admitida em serviço de urgência após 2 horas de episódio de convulsão tônico-clônica generalizada em junho de 2013. Já há 2 meses desde a admissão vinha apresentando tremores de intenção, principalmente em membros superiores, os quais pioraram progressivamente durante a evolução, chegando a limitar a realização de suas atividades usuais. $\mathrm{O}$ episódio convulsivo inicial foi investigado, tendo sido iniciado anticonvulsivante via oral após alta hospitalar. Negava antecedentes de epilepsia. Ao final do segundo mês após a admissão inicial, apresentou novo episódio convulsivo, sendo internada para compensação clínica. Referia, como sintomas associados, cãibras em membros inferiores e tremores em membros superiores, que persistiam durante todo o dia. A paciente não apresentou episódios de febre nem outros sinais de doenças sistêmicas. $\mathrm{O}$ volume urinário mantinha-se normal.

Apresentava como histórico de medicações o uso contínuo de Omeprazol (20mg/dia) - este há 6 anos, Hidroclorotiazida (25mg/dia), Losartana (100mg/dia), Clopidogrel (75mg/dia), Ácido 
acetilsalicílico (81mg/dia), Rosuvastatina (20mg/dia) e Fenitoína (300 mg/dia).

Ao exame clínico, apresentava estado geral bom, hidratada, afebril, consciente, anictérica e acianótica. Não apresentava sinais de alterações em cadeias linfonodais. O exame do aparelho respiratório demonstrou frequência respiratória de 17 incursões por minuto, murmúrio vesicular presente e sem ruídos adventícios. A frequência cardíaca era de 85 bpm e a paciente encontrava-se normotensa. À ausculta, apresentava ritmo cardíaco em 2 tempos, sem sopros. Os pulsos periféricos eram simétricos, cheios e amplos, bilateralmente. Não foi observado edema em membros inferiores. Abdome com ruídos hidroaéreos presentes, flácido, sem distensão, sem visceromegalias ou massas palpáveis. O exame neurológico foi compatível com a normalidade.

Na admissão (18/07/13), os exames bioquímicos apresentaram as seguintes concentrações séricas: magnésio 0,94 mg/dL, sódio 144,0 mmol/L; potássio 4,40 $\mathrm{mmol} / \mathrm{L}$, creatinina $0,84 \mathrm{mg} / \mathrm{dL}$ e cálcio: 9,80 $\mathrm{mg} / \mathrm{dL}$. Exames de Eletroencefalografia e Tomografia Computadorizada de crânio normais.

Inicialmente, atribuiu-se a alteração do $\mathrm{Mg}$ sérico como sendo decorrente do uso diário de Hidroclorotiazida, tendo em vista a clássica associação entre ambos. Um dia após a realização dos primeiros exames, foi suspensa a administração dessa droga. Concomitante a essa suspensão, procedeu-se à reposição de Sulfato de Mg a 10\%, intravenoso. Com melhora sintomática e nível de magnésio sérico nor- mal (2,0 mg/dL), recebeu alta hospitalar.

Aproximadamente um mês após a alta, já sem uso de Hidroclorotiazida, a paciente procurou novamente atendimento médico referindo os mesmos sintomas iniciais. Nessa ocasião, apresentava concentrações séricas de magnésio $(0,98 \mathrm{mg} / \mathrm{dL})$ e cálcio total $(8,0 \mathrm{mg} / \mathrm{dL})$, quando foi iniciada reposição oral com Pidolato de Magnésio 1,5 g (130 mg do íon magnésio), duas vezes ao dia. Após cerca de 10 dias, o magnésio sérico era $1,30 \mathrm{mg} / \mathrm{dL}$, mesmo com reposição diária. Nessa ocasião, o Omeprazol foi suspeitado como agente causal da hipomagnesemia e substituído por Cloridrato de Ranitidina. Após duas semanas, a concentração de magnésio sérico era de 1,62 mg/dL e de cálcio total $8,80 \mathrm{mg} / \mathrm{dL}$. A dosagem de vitamina $\mathrm{D}$ total nesta data foi de $31 \mathrm{ng} / \mathrm{mL}$. Reduziu-se, então, a dosagem do Pidolato de Magnésio, ajustando a posologia para apenas uma tomada diária. Duas semanas após, novos exames revelaram $\mathrm{Mg}$ de 2,04 mg/dL. Devido à manutenção da normalidade, suspendeu-se a reposição de magnésio, a fim de que nova dosagem fosse realizada. Após duas semanas, o valor do $\mathrm{Mg}$ sérico foi de 2,50 mg/dL, mesmo sem reposição. Após um mês sem uso de qualquer reposição desse íon, o nível sérico manteve-se normal (Tabela 1).

Como houve melhora neurológica da paciente, o anticonvulsivante foi retirado e não houve, até o momento, recorrência dos tremores ou dos episódios convulsivos.

A tabela 1 mostra as dosagens séricas com suas respectivas datas.

Tabela 1: Valores e datas de dosagens séricas de Magnésio, Cálcio Total e Creatinina

\begin{tabular}{|c|c|c|c|c|}
\hline Datas & $\begin{array}{l}\text { Magnésio sérico } \\
(1,6-2,5 \mathrm{mg} / \mathrm{dL})\end{array}$ & $\begin{array}{c}\text { Magnésio sérico } \\
(1,4-2,1 \mathrm{mEq} / \mathrm{L})\end{array}$ & $\begin{array}{c}\text { Cálcio Total } \\
(8,8-10,6 \mathrm{mg} / \mathrm{dL})\end{array}$ & $\begin{array}{c}\text { Creatinina } \\
(0,5-1,3 \mathrm{mg} / \mathrm{dL})\end{array}$ \\
\hline $18 / 07 / 13$ & $0,94 \Downarrow$ & $0,78 \Downarrow$ & $9,8 \Leftrightarrow$ & $0,84 \Leftrightarrow$ \\
\hline $27 / 08 / 13$ & $0,98 \Downarrow$ & $0,80 \Downarrow$ & $8,0 \Downarrow$ & - \\
\hline \multirow[t]{2}{*}{ 06/09/13 } & $1,30 \Downarrow$ & $1,06 \Downarrow$ & $8,0 \Downarrow$ & - \\
\hline & \multicolumn{4}{|c|}{ Suspensão do Omeprazol } \\
\hline $19 / 09 / 13$ & $1,62 \Leftrightarrow$ & $1,40 \Leftrightarrow$ & $8,8 \Leftrightarrow$ & $0,70 \Leftrightarrow$ \\
\hline \multirow[t]{2}{*}{$02 / 10 / 13$} & $2,04 \Leftrightarrow$ & $1,67 \Leftrightarrow$ & - & - \\
\hline & \multicolumn{4}{|c|}{ Suspensão da reposição oral de Magnésio } \\
\hline $15 / 10 / 13$ & $2,50 \Leftrightarrow$ & $2,05 \Leftrightarrow$ & - & - \\
\hline $15 / 11 / 13$ & $2,50 \Leftrightarrow$ & $2,05 \Leftrightarrow$ & - & $0,90 \Leftrightarrow$ \\
\hline
\end{tabular}




\section{Discussão}

A utilização crônica de IBP deve ser considerada como uma das causas de hipomagnesemia, especialmente quando não forem encontrados fatores etiológicos mais comuns. Nessa situação, conforme visto no presente caso, a terapêutica mais eficiente corresponde à simples retirada do IBP, restaurando, assim, a homeostase do referido íon.

$\mathrm{O}$ correto balanço corpóreo do $\mathrm{Mg}$ é essencial para o funcionamento de vários processos intracelulares. Sua regulação se dá através de um processo dinâmico entre absorção gastrointestinal, absorção renal pela alça de Henle, absorção e reabsorção de reservatórios em matriz óssea e excreção renal. ${ }^{10,11} \mathrm{Di}$ versos estudos tem relacionado o uso de IBP com hipomagnesemia e hipocalcemia, provavelmente pela diminuição da absorção gastrointestinal decorrente de atrofia parcial da mucosa. Enquanto a hipocalcemia pode ser remediada pela suplementação de cálcio, a hipomagnesemia pode ser tratada apenas pela interrupção do IBP. ${ }^{12}$

Os mecanismos bioquímicos pelos quais a absorção gastrointestinal de Mg ocorre podem ser divididos em transportes ativo e passivo. Thongon e Krishnamra mostraram que o Omeprazol tem, claramente, um efeito inibidor sobre a absorção passiva de $\mathrm{Mg}$, inibindo a função de canais paracelulares desse íon, mas com muito menos efeito sobre a absorção passiva de cálcio. O Omeprazol já era sabidamente capaz de diminuir a intensidade do campo elétrico negativo, provocando, portanto, seletividade catiônica em canais paracelulares do trato gastrointestinal. ${ }^{10,12}$ Além disso, Epstein et al. evidenciaram o efeito da hipomagnesemia como causa secundária de hipocalcemia apesar de valores normais de níveis de vitamina $\mathrm{D}$, havendo também uma relação dos baixos níveis de cálcio com diminuição concomitante dos valores de paratormônio (PTH), devido a uma resistência do PTH ao cálcio. ${ }^{8}$ Segundo Mackay e Bladon, a associação de hipocalcemia e hipomagnesemia induzida por IBP está presente em $64 \%$ dos casos. ${ }^{7}$

A paciente descrita neste estudo apresentou hipomagnesemia e hipocalcemia enquanto fazia uso de Omeprazol, apresentando nível de vitamina D adequado. A implementação do tratamento com reposição de $\mathrm{Mg}$, simultaneamente ao uso de IBP, não foi capaz de reverter os quadros de hipomagnesemia e hipocalcemia, que só foram solucionados após a suspensão do Omeprazol.
O tempo necessário para que o IBP interfira na absorção gastrointestinal de $\mathrm{Mg}$ é muito variável. Hess et al., em revisão sistemática, concluíram que esse tempo varia desde duas semanas até 13 anos de uso contínuo, com uma mediana de 5,5 anos para poder induzir a hipomagnesemia. ${ }^{10,13}$ A paciente retratada neste caso se insere nesse contexto, tendo em vista que faz uso contínuo de Omeprazol há 6 anos. Fazia também uso diário há 6 anos de Rosuvastatina e Ácido acetilsalicílico.

Segundo Mackay e Bladon, suplementos orais de $\mathrm{Mg}$ seriam, na melhor das hipóteses, apenas parcialmente eficazes na correção da hipomagnesemia enquanto a terapia com IBP era mantida. Infusões intravenosas de $\mathrm{Mg}$ produziam, por curto prazo, melhora nos níveis séricos. A dificuldade para reverter a hipomagnesemia desses pacientes ainda em uso de IBP contrastava com a facilidade em obter a normalidade com a simples suspensão do IBP. A associação das duas estratégias gerou notáveis melhorias no bemestar dos pacientes ${ }^{7,8}$, o que também foi evidenciado na paciente em questão.

A prevalência de hipomagnesemia induzida por IBP ainda não é conhecida. Os sintomas da hipomagnesemia são, em sua maioria, inespecíficos ou podem ser mal interpretados. Além disso, as dosagens de $\mathrm{Mg}$ sérico não fazem parte da rotina da determinação do perfil bioquímico dos pacientes.

A terapia com IBP a longo prazo deve ser, portanto, objeto de avaliação regular, sendo sugerido que o Mg sérico seja dosado anualmente ou na vigência de algum sintoma que possa orientar para a deficiência desse íon. ${ }^{7}$

\section{Conclusão}

Como evidenciado no presente caso, a hipomagnesemia induzida pelo uso crônico de IBP é uma condição que pode levar a consequências clínicas graves, que, se não tiverem a intervenção adequada, podem levar, inclusive, ao óbito. Contrapondo-se à gravidade que essa situação clínica pode proporcionar, a terapêutica apresenta-se como uma medida de fácil manejo, evidenciada pela simples suspensão do IBP, medida capaz de restaurar o equilíbrio homeostático do Mg.

Mesmo diante da importância já evidenciada, a hipomagnesemia não é frequentemente identificada e seus efeitos sistêmicos são confundidos com outras entidades nosológicas e, raramente, relaciona- 
dos ao uso de IBP. Dada a prescrição universalizada desses medicamentos e o desconhecimento acerca dos efeitos adversos que eles podem causar, tal temática, evidenciada através deste relato de caso, adquire notória relevância clínica, merecendo atenção por parte da comunidade médica como um todo.

\section{Referênclas}

1. Dimke H, Monnens L, Hoenderop JG, Bindels RJ. Evaluation of hypomagnesaemia: lesons from disorders of tubular transport. Am J Kidney Dis. 2013; 62:377-83.

2. Faulhaber GAM, Ascoli BM, Lubini A, Mossmann M, Rossi G, Geib G, et al. Serum magnesium and proton-pump inhibitors use: a cross-sectional study. Rev Assoc Med Bras. 2013;59: 276-9.

3. Lameris AL, Monnens LA, Bindels RJ, et al. Drug-induced alterations in Mg2+ homeostasis. Clin Sci (Lond). 2012;123:1-14.

4. Cunha DF, Bianco MP, Lenza RM, Cunha SFC. Resposta de fase aguda e níveis séricos de magnésio em pacientes hospitalizados. Rev Assoc Med Bras. 1999; 45: 142-6.

5. Agus ZS. Hypomagnesaemia. J Am Soc Nephrol. 1999; 10:1616-22.
6. Weisinger JR, Bellorín-Font E. Magnesium and phosphorus. Lancet. 1998;352(9125):391-6.

7. Mackay JD and Bladon PT. Hypomagnesaemia due to proton-pump inhibitor therapy: a clinical case series. QJM. 2010;103:387-95.

8. Epstein M, McGrath S, Law F. Proton-pump inhibitors and hypomagnesemic hypoparathyroidism. N Engl J Med. 2006; 355:1834-6.

9. Agarwal N, Rees A, Scanlon M. Hypomagnesaemia related to proton-pump inhibition. Endocrine Abstracts. 2008; 15: 24.

10. Gandhi NY, Sharif WK, Chadha S, Shakher J. A Patient on Long-Term Proton Pump Inhibitors Develops Sudden Seizures and Encephalopathy: An Unusual Presentation of Hypomagnesaemia. Case Rep Gastrointest Med. 2012;2012:632-721.

11. Negri AL, Valle EE. Hypomagnesaemia/hypokalemia associated with the use of esomeprazole. Curr Drug Saf. 2011;6:2046 .

12. Thongon N, Krishnamra N. Apical acidity decreases inhibitory effect of omeprazole on Mg2+ absorption and claudin-7 and 12 expression in Caco-2 monolayers. Exp Mol Med. 2012;44:684-93.

13. Hess MW, Hoenderop JGJ, Bindels RJM, Drenth JPH. Systematic review: hypomagnesaemia induced by proton pump inhibition. Aliment Pharmacol Ther.. 2012;36:405-13. 